\title{
PECTINASES: APLICAÇÕES INDUSTRIAIS E PERSPECTIVAS
}

\author{
Mariana Uenojo* e Glaucia Maria Pastore \\ Departamento de Ciência de Alimentos, Faculdade de Engenharia de Alimentos, Universidade Estadual de Campinas, CP 6121, \\ 13083-862 Campinas - SP, Brasil
}

Recebido em 15/8/05; aceito em 16/5/06; publicado na web em 19/1/07

\begin{abstract}
PECTINOLYTIC ENZYMES. INDUSTRIAL APPLICATIONS AND FUTURE PERSPECTIVES. Pectic substances are structural heteropolysaccharides that occur in the middle lamellae and primary cell walls of higher plants. They are composed of partially methylesterified galacturonic acid residues linked by $\alpha-1,4$-glycosidic bonds. Pectinolytic enzymes are complex enzymes that degrade pectic polymers and there are several classes of enzymes, which include pectin esterases, pectin and pectate lyases and polygalacturonases. Plants, filamentous fungi, bacteria and yeasts are able to produce pectinases. In the industrial world, pectinases are used in fruit juice clarification, in the production of wine, in the extraction of olive oil, fiber degumming and fermentation of tea, coffee and cocoa.
\end{abstract}

Keywords: pectic substances; pectinolytic enzymes; industrial applications.

\section{INTRODUÇÃO}

As pectinases formam um grupo de enzimas que degradam substâncias pécticas, hidrolisando ligações glicosídicas ao longo da cadeia carbônica. Podem ser despolimerizantes ou desesterificantes e são produzidas por plantas, fungos filamentosos, bactérias e leveduras. Algumas das aplicações destas enzimas nas indústrias de alimentos incluem amadurecimento de frutas, clarificação e redução de viscosidade em sucos de frutas, tratamento preliminar do suco de uva para indústrias vinícolas, extração de polpa de tomate, fermentação de chá e chocolate, tratamento de resíduos vegetais, degomagem de fibras nas indústrias têxtil e de papel, nutrição animal, enriquecimento protéico de alimentos infantis e extração de óleos.

\section{HISTÓRICO}

As pectinases foram algumas das primeiras enzimas a serem utilizadas comercialmente nas preparações de vinhos e sucos de frutas ao redor de $1930^{1,2}$ e somente a partir de 1960, quando os estudos sobre a natureza química de tecidos vegetais se tornaram mais aparentes, é que os cientistas começaram a utilizar as enzimas mais eficientemen$\mathrm{te}^{2}$. Durante as duas últimas décadas, o uso de celulases, hemicelulases e pectinases têm aumentado consideravelmente, especialmente nas indústrias de alimentos, bebidas e vinhos, têxtil e de papel e celulose ${ }^{1}$.

Diversas companhias na Europa (Novo Nordisk, Miles KaliChemie, Swiss Ferment Co., Novartis, Roche), Estados Unidos (Miles Laboratories, Rohm and Raas Co.) e no Japão (Kikkoman Shoyu Co.) produzem pectinases e preparações comerciais de pectinases $^{1,3,4}$. Atualmente, essas enzimas correspondem a cerca de $25 \%$ do mercado mundial de enzimas ${ }^{5}$. O valor estimado de vendas em 1995 foi de US\$ 1 bilhão, dos quais US\$ 75 milhões somente com pectinases ${ }^{2,3}$. Para 2005, o valor de vendas esperado para a indústria de enzimas é de US\$ 1,7 a 2 bilhões ${ }^{2}$.

\section{SUBSTÂNCIAS PÉCTICAS}

Substâncias pécticas são macromoléculas glicosídicas de alto peso molecular que formam o maior componente da lamela média, uma fina

*e-mail:mariu@fea.unicamp.br camada de material adesivo extracelular entre as paredes primárias de células de vegetais superiores ${ }^{5-7}$. Quimicamente, são um complexo coloidal de polissacarídeos ácidos, composto de resíduos de ácido galacturônico unidos por ligações $\alpha-1,4$, parcialmente esterificados por grupos metil éster ${ }^{2,3,8}$ e parcial ou completamente neutralizadas por uma ou mais bases (íons sódio, potássio ou amônio) $)^{2,4,5}$.

Ao contrário das proteínas, lipídeos e ácidos nucléicos, e sendo polissacarídeos, as substâncias pécticas não possuem massa molecular definida, variando de 25 a $360 \mathrm{kDa}^{4}$.

A Sociedade Americana de Química (American Chemical Society) classificou as substâncias pécticas em: protopectina, ácido pectínico, ácido péctico e pectina, sendo estes três últimos total ou parcialmente solúveis em água ${ }^{2,6}$.

Protopectina é insolúvel em água, é a forma nativa unida com outros constituintes das células vegetais ${ }^{10} \mathrm{e}$, em condições de hidrólise restrita, produzem ácidos pectínicos ou pectina ${ }^{2,4,5,11}$. Ácido péctico é uma designação aplicada a substâncias pécticas compostas de ácido poligalacturônico coloidal ${ }^{2,4}$, onde os grupos carboxilas estão essencialmente livres de grupos metil éster ${ }^{2,410}$ e seus sais são pectatos neutros ou ácidos ${ }^{5,11}$. Ácido pectínico é um grupo de compostos contendo ácido poligalacturônico coloidal com poucos grupos metil éster ${ }^{4,5,10}$.

O termo geral pectina (Figura 1) designa ácidos pectínicos solúveis em água, com grau variável de grupos metil éster e um grau de neutralização capaz de formar gel com açúcares e ácidos em condições adequadas ${ }^{4}$. Consiste em uma estrutura de ligações axiais de unidades de ácido $\alpha-1$, 4-D-galacturônico e contém moléculas de L-ramnose, arabinose, galactose e xilose como correntes laterais $^{3,6,12-14}$. "Pectinas com alto teor de metoxilas" (acima de 50\%) são freqüentemente denominadas apenas "pectinas" e têm poder de geleificação na presença de açúcares e ácidos, enquanto que a geleificação de pectinas com baixo teor de metoxilação é possível na ausência de açúcares e na presença de alguns íons metálicos ${ }^{4,13}$.

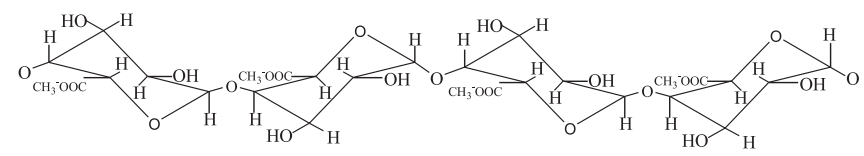

Figura 1. Estrutura primária de uma molécula de pectina. Não estão incluídos resíduos de ramnose, galactose, arabinose e xilose. Adaptado da ref. 6 


\section{ENZIMAS PECTINOLÍTICAS}

As substâncias pécticas podem ser degradadas por enzimas pectinolíticas, produzidas em diferentes combinações pelas plantas e por microrganismos como fungos, leveduras e bactérias ${ }^{12,15,16}$. São muito utilizadas nas indústrias de sucos de frutas para reduzir viscosidade e melhorar e aumentar a eficiência de filtração e de clarificação $0^{3,7,13,17-24}$; no tratamento preliminar da uva em indústrias vinícolas; na maceração, liquefação e extração de tecidos vegetais; na fermentação de chá, café e cacau ${ }^{7,12}$; para melhorar a extração de óleos vegetais ${ }^{12,21-24}$; na extração de polpa de tomate $^{7}$ e no tratamento e degomagem de fibras naturais para as indústrias têxtil e de papel $^{7,18,21-24}$.

As pectinases também são utilizadas para reduir o de amargor excessivo em cascas de citrus, restaurar o aroma perdido durante secagem e melhorar a firmeza de pêssego e picles processados. A infusão de pectinase e $\beta$-glicosidase aumenta o aroma e as substâncias voláteis de frutas e vegetais, aumenta a quantidade de agentes antioxidantes em óleo de oliva extravirgem e reduz a indução ao ranço ${ }^{1}$, além de outras aplicações (Tabela 1).

A habilidade para sintetizar enzimas pectinolíticas é muito comum entre os grupos de microrganismos (Tabela 2), mas os fungos são os preferidos em escala industrial, pois cerca de $90 \%$ das enzimas produzidas podem ser secretadas no meio de cultura ${ }^{23}$.

A síntese destas enzimas sofre influência dos componentes do meio de cultura, particularmente da fonte de carbono, presença de indutores (pectina e derivados $)^{3,23}$ e das condições de cultivo, como
pH, temperatura, aeração, agitação e tempo de incubação ${ }^{20}$. Com relação às técnicas de fermentação, a fermentação em estado sólido geralmente é preferida por permitir a produção de enzimas brutas mais concentradas e, conseqüentemente, com menores custos de extração e purificação ${ }^{25,26}$. Substratos típicos são resíduos agroindustriais, como cascas de frutas cítricas, bagaço de beterraba doce e extratos de farelo de trigo ${ }^{23,27}$, por serem fontes de energia alternativa para crescimento e metabolismo e por estarem abundantemente disponíveis ${ }^{18,26,27}$.

A classificação das enzimas pécticas está baseada no ataque ao esqueleto galacturônico ${ }^{6}$, pela preferência de substrato (pectina, ácido péctico ou protopectina), ação por transeliminação ou hidrólise e por clivagem randômica (enzima endo-, liqüidificante ou despolimerizante) ou terminal (enzima exo- ou sacarificante) $)^{2,4,22,26}$.

Existem basicamente três tipos de pectinases (Figura 2): pectina esterase (desesterificante ou desmetoxilante) remove os grupos metil éster; as despolimerizantes (incluem as enzimas hidrolíticas e as liases) catalisam a clivagem das ligações glicosídicas das substâncias pécticas e, as protopectinases que solubilizam protopectina para formar pectina ${ }^{4,5}$. Estas enzimas foram classificadas e nomeadas de acordo com a "Enzyme Comission" (EC), segundo as recomendações da IUPAC-IUB ${ }^{3,5}$ (Tabela 3).

\section{Enzima desmetoxilante ou desesterificante}

A pectina esterase (polimetilgalacturonato esterase, PMGE) catalisa a hidrólise dos grupos metil éster da pectina, liberando metanol

Tabela 1. Funções e aplicações das pectinases na indústria de alimentos e de vinhos

\begin{tabular}{lll}
\hline ENZIMA & FUNÇÃO & APLICAÇÃO \\
\hline $\begin{array}{l}\text { Enzimas de maceração } \\
\text { (pectinases, celulases e hemicelulases). }\end{array}$ & $\begin{array}{l}\text { Hidrólise de pectina solúvel e de componentes } \\
\text { de paredes celulares, diminuição de viscosidade } \\
\text { e manutenção de textura de sucos de frutas. }\end{array}$ & $\begin{array}{l}\text { Melhoramento na extração de sucos de frutas e } \\
\text { de óleo de oliva, liberação de aromas, enzimas, } \\
\text { proteínas, polissacarídeos, amido e ágar. }\end{array}$
\end{tabular}

Pectinase ácida e termo-estável com poligalacturonase, pectina esterase e pectina transeliminase.

Poligalacturonase com alta atividade de pró-pectinase e baixa celulase.

Poligalacturonase e pectina transeliminase com baixa atividade de pectina esterase e hemicelulase.

Poligalacturonase, pectina transeliminase e hemicelulase.

Pectinase e $\beta$-glicosidase.

Pectina esterase com atividade de poligalacturonase e de pectina liase.

Pectina esterase.

Enzimas de maceração (pectinases, celulases e hemicelulases).
Rápida diminuição de viscosidade e quebra dos tecidos vegetais.

Hidrólise parcial de pró-pectina.

Hidrólise parcial de pró-pectina e de pectina solúvel em fragmentos de tamanho médio, formação de precipitado e remoção de hidrocolóides de celulose.

Hidrólise completa de pectina e de polissacarídeos ramificados.

Infusão de pectinase e glicosidase para facilitar o descascamento e melhorar a firmeza de frutas e frutas e vegetais. vegetais.

Processamento de frutas.

Desesterificação e geleificação de pectina.

Hidrólise de polissacarídeos das paredes celulares vegetais.
Melhora o rompimento da fruta e aumenta a extração de pigmentos de cor.

Produção de purês com alta viscosidade.

Produção de sucos vegetais não clarificados de baixa viscosidade.

Clarificação de sucos de frutas.

Alteração das propriedades sensoriais de

Produção de ketchup de alta qualidade e de polpas de frutas.

Melhoramento na clarificação de cidra.

Melhoramento da maceração da casca e extração de pigmentos de cor de uvas, qualidade, estabilidade, filtração e clarificação de vinhos.

Adaptada da ref. 1 
Tabela 2. Ocorrência de enzimas pécticas em alguns microrganismos

\begin{tabular}{|c|c|c|c|c|c|c|c|}
\hline MICRORGANISMO & PMGE & PG & PGL & PMG & PMGL & OG & OGL \\
\hline Aspergillus niger & + & + & & + & + & & \\
\hline Aspergillus sojae & & & & & + & & \\
\hline Aspergillus saito & & + & & & & & \\
\hline Bacillus sp & & & + & & & + & \\
\hline Bacillus subtilis & & & + & & & & \\
\hline Bacillus polymixa & & & + & & & & \\
\hline Bacillus pumilus & & & + & & & & \\
\hline Bacillus sphaericus & & & + & & & & \\
\hline Bacillus stearothermophilus & & & + & & & & \\
\hline Cercocpora arachidicola & & + & & & & & \\
\hline Cephalosporium $s p$ & & & + & & & & \\
\hline Clostridium multifermentans & + & & + & & & & \\
\hline Clostridium aurantibutyricum & + & & + & & & & \\
\hline Clostridium felsineum & & + & + & & & & \\
\hline Cytophaga johnsonii & & & + & & & & \\
\hline Cytophaga deprimata & & & + & & & & \\
\hline Cytophaga albogilva & & & + & & & & \\
\hline Erwinia aroideae & & + & + & & + & & + \\
\hline Erwinia carotovora & & + & + & & & & + \\
\hline Fusarium culmorum & & & + & & & & \\
\hline Fusarium oxysporum & & & + & & & & \\
\hline Fusarium solani & & & + & & + & & \\
\hline Penicillium expansum & & + & & & & & \\
\hline Penicillium italicum & & & & & + & & \\
\hline Penicillium digitatum & + & & & + & + & & \\
\hline Penicillium chrysogenum & + & + & & & & & \\
\hline Pseudomonas sp & & & + & & & & + \\
\hline Pseudomonas fluorescens & & & + & & & & \\
\hline Pseudomonas marginalis & + & + & + & & & & \\
\hline Rhizoctania fragariae & & + & & & & & \\
\hline Rhizoctania solani & + & + & & & & & \\
\hline Rhizopus arrhizus & & + & & & & & \\
\hline Streptomyces nitrosporeus & & & + & & & & \\
\hline Trichoderma koningii & & + & & & & & \\
\hline Trichoderma pseudokoningii & & + & & & & & \\
\hline Xanthomonas $s p$ & + & & + & & & & \\
\hline Xanthomonas campestris & + & & + & & & & \\
\hline Xanthomonas cyanopsidis & & & + & & & & \\
\hline
\end{tabular}

PMGE: pectina esterase, PG: poligalacturonase, PGL: poligalacturonato liase, PMG: polimetilgalacturonase, PMGL: polimetilgalacturonato liase, OG: oligogalacturonase, OGL: oligogalacturonídeo liase. Adaptada das refs. 4, 5, 14 e 28

Tabela 3. Classificação das enzimas pécticas

\begin{tabular}{lccc}
\hline Tipo de pectinase & Nome sugerido pela EC & Sigla & Nome comum \\
\hline Desesterificante & polimetilgalacturonase esterase & PMGE & pectina esterase \\
Hidrolase & endo poligalacturonase & endo-PG & poligalacturonase \\
& exo poligalacturonase 1 & exo-PG 1 & poligalacturonase \\
& exo poligalacturonase 2 & exo-PG 2 & poligalacturonase \\
& endo polimetilgalacturonase & endo-PMG & pectina hidrolase \\
& exo polimetilgalacturonase & exo-PMG & pectina hidrolase \\
endo poligalacturonase liase & endo-PGL & pectato liase \\
Liase & exo poligalacturonase liase & exo-PGL & pectato liase \\
& endo polimetilgalacturonato liase & endo-PMGL & pectina liase \\
& exo polimetilgalacturonato liase & exo-PMGL & pectina liase
\end{tabular}

Pectinases que atuam sobre oligogalacturonatos não estão incluídas na tabela porque não são muito abundantes e possuem pouco interesse industrial na degradação de pectina. Adaptada das refs. 5 e 6 


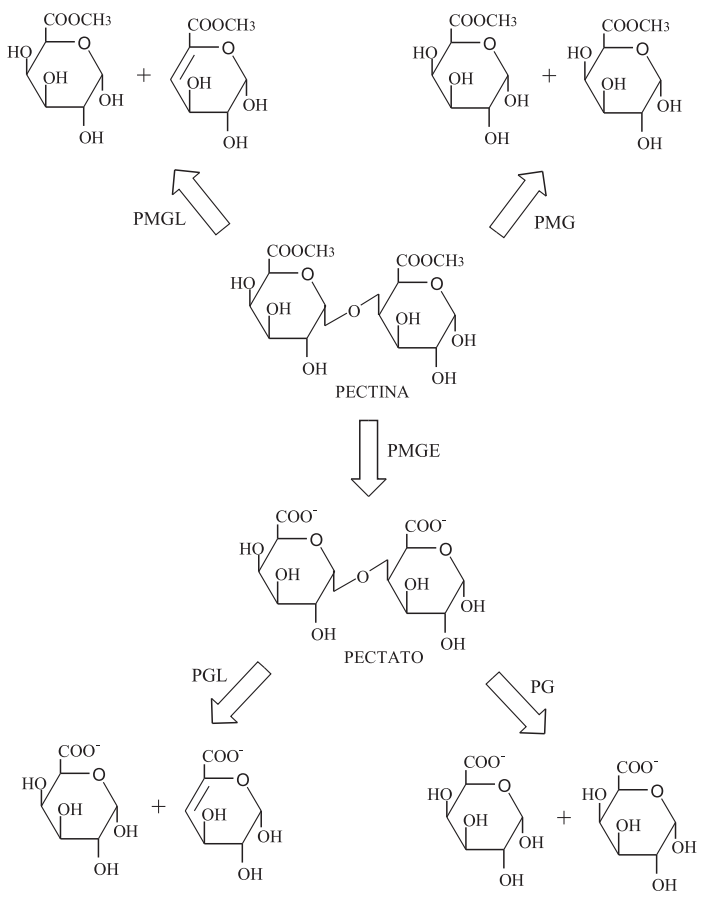

Figura 2. Modo de ação enzimática das pectinases em uma molécula de pectina. PMGL: polimetilgalacturonato liase. PMG: polimetilgalacturonase. PMGE: polimetilgalacturonato esterase (pectina esterase). PGL: poligalacturonato liase (pectato liase). PG: poligalacturonase. Adaptado da ref. 6

e convertendo pectina em pectato (polímero não esterificado) ${ }^{3,5,29}$. Age preferencialmente no grupo metil éster da unidade de galacturonato próxima a uma unidade não esterificada ${ }^{28}$, apresenta valores de $\mathrm{pH}$ ótimo variando de 4 a 8 e temperatura ótima de 40 a $50{ }^{\circ} \mathrm{C}^{5}$. Está presente em praticamente todas as preparações enzimáticas comerciais para proteção e melhoramento da textura e firmeza de frutas e vegetais processados e na extração e clarificação de sucos de frutas. Pode estar envolvida em mudanças das substâncias pécticas durante amadurecimento, estocagem e processamento de frutas e vegetais ${ }^{5,6}$.

\section{Enzimas despolimerizantes}

As enzimas despolimerizantes são classificadas de acordo com a clivagem hidrolítica (hidrolases) ou transeliminativa (liases) das ligações glicosídicas; mecanismos endo- (randômica) ou exo- (a partir do final da molécula) de ação e preferência por ácido péctico ou pectina como substrato. Envolvem as hidrolases (catalisam a hidrólise de ligações $\alpha-1,4$ ) e as liases (catalisam a $\beta$-eliminação) ${ }^{6,15}$.

\section{Hidrolases}

As hidrolases incluem as polimetilgalacturonases e as poligalacturonases.

A polimetilgalacturonase (PMG) presumivelmente hidrolisa polimetil-galacturonatos a oligometilgalacturonatos ${ }^{30}$ por clivagem de ligações $\alpha-1,4$, podendo ser endo- ou exo-PMG ${ }^{28}$. Apesar da PMG ser citada em algumas literaturas, sua existência é questionada por alguns autores ${ }^{4,30}$.

As poligalacturonases (PG) hidrolisam $\alpha-1,4$ ligações glicosídicas entre dois resíduos de ácido galacturônico ${ }^{31}$. É a maior enzima com função hidrolítica, podendo apresentar ação endo(hidrólise randômica) ou exo- (hidrólise seqüencial) do ácido péctico $^{5,28}$. As poligalacturonases fúngicas são úteis pela alta atividade enzimática e possuirem $\mathrm{pH}$ ótimo de atividade na região levemente ácida e temperatura ótima entre 30 e $50{ }^{\circ} \mathrm{C}^{5,22}$.
Liases

As liases, também chamadas transeliminases, rompem ligações glicosídicas resultando em galacturonídeos com uma ligação insaturada entre os carbonos 4 e 5 do final não redutor do ácido galacturônico formado $^{5,28}$ e incluem as pectina liases e as pectato liases.

Pectina liase (polimetilgalacturnato liase, PMGL) catalisa a $\beta$ eliminação entre dois resíduos de ácido galacturônico mais ou menos esterificados. Quebram as ligações por transeliminação do hidrogênio dos carbonos das posições 4 e 5 da porção aglicona do substrato (pectina) ${ }^{10,15,32}$ de modo endo- ou exo-. O pH ótimo é em torno de $5,5^{33}$ e temperatura ótima entre 40 e $50{ }^{\circ} \mathrm{C}^{5}$.

Pectato liase (poligalacturonato liase, PGL) catalisa a clivagem de ligações $\alpha-1,4$ de ácido péctico de modo endo- ou exo- por transeliminação ${ }^{28}$, requer $\mathrm{Ca}^{2+}$ para atividade e tem $\mathrm{pH}$ ótimo na região alcalina, entre 7,5 e 10 e temperatura ótima entre 40 e $50{ }^{\circ} \mathrm{C}^{4,5,33}$.

\section{Protopectinases}

Estas enzimas solubilizam protopectina, formando pectina solúvel altamente polimerizada ${ }^{28}$. Com base nas suas aplicações, são principalmente de dois tipos: protopectinase tipo A (PPase-A), que reage com o sítio interno, isto é, a região do ácido poligalacturônico da protopectina e, protopectinase tipo B (PPase-B) que reage com o sítio externo, ou seja, com as cadeias de polissacarídeos que podem estar conectadas às cadeias de ácido poligalacturônico, constituintes das paredes celulares ${ }^{5}$. Não são muito abundantes e possuem pouco interesse industrial na degradação da pectina ${ }^{6}$.

\section{UTILIZAÇÃO DE RESÍDUOS AGROINDUSTRIAIS PARA PRODUÇÃ̃O DE ENZIMAS PECTINOLÍTICAS}

A economia brasileira é uma das mais importantes economias do mundo baseadas na agricultura, produzindo e exportando café, açúcar de cana, soja, mandioca, frutas, entre outros. Entretanto, a grande produção desses produtos agrícolas gera uma grande quantidade de resíduos ${ }^{34}$. Nos últimos anos houve um aumento na tentativa de tornar mais eficiente a utilização desses resíduos, cuja disposição no meio ambiente causa sérios problemas de poluição. Com o advento da inovação biotecnológica na área de enzimas e tecnologia das fermentações, novas perspectivas estão sendo criadas ${ }^{35}$. Umas das aplicações em potencial desses resíduos pode ser sua utilização como fonte de carbono em bioprocessos para obtenção de produtos químicos e de produtos de maior valor agregado, como enzimas, álcoois, proteínas, ácidos orgânicos, aminoácidos, metabólitos secundários biologicamente ativos e compostos de $\operatorname{aroma}^{27,34,36}$.

\section{APLICAÇÕES DAS ENZIMAS PECTINOLÍTICAS}

\section{Indústrias de sucos de frutas}

As substâncias pécticas são responsáveis pela consistência, turbidez e aparência dos sucos das frutas, e sua presença causa um aumento considerável na viscosidade do suco, dificultando a filtração e a concentração ${ }^{6,13}$. A adição de enzimas pectinolíticas nos purês de frutas e vegetais resulta na degradação da pectina e outros componentes de alto peso molecular ${ }^{25,37}$, diminuindo a viscosidade e aumentando o rendimento dos sucos ocasionando uma aparência cristalina no produto final e reduzindo em até $50 \%$ o tempo de filtração $0^{5,13,20}$.

Durante meados da década de 30, quando as indústrias de frutas começaram a produzir sucos, o rendimento era baixo e muitas dificuldades foram encontradas para filtrar o suco e se atingir uma 
clarificação estável. A partir de então, pesquisas utilizando pectinases, celulases e hemicelulases de microrganismos, juntamente com o conhecimento dos componentes vegetais das frutas, diminuíram essas dificuldades ${ }^{1,5}$.

A combinação de pectinases, celulases e hemicelulases, chamadas coletivamente de enzimas de maceração, é usada na extração e clarificação de sucos de frutas e vegetais ${ }^{12,18-20}$. A adição de $\alpha$-amilase e amiloglicosidase, ativas a $\mathrm{pH}$ ácido, é usada no processamento de frutas contendo amido, especialmente maçã, para prevenir turvação $0^{1,4,14,38,39}$.

O tratamento enzimático conduz a uma extensa degradação da lamela média e da pectina das paredes celulares por ação de poligalacturonase, pectina metil esterase e pectina liase. $\mathrm{O}$ efeito sinergístico da combinação de pectinases e celulases é um processo crucial no tratamento enzimático da polpa para uma quase completa liquefação das frutas e dos vegetais ${ }^{17,40}$. A hidrólise enzimática das paredes celulares aumenta o rendimento de extração, diminui o conteúdo de açúcares, de matéria seca solúvel, de ácidos galacturônicos e a acidez titulável. A polpa resultante tem baixa viscosidade e a quantidade de resíduos da polpa é reduzida ${ }^{40}$.

$\mathrm{O}$ uso de enzimas de maceração aumenta o rendimento da extração e melhora o processamento, sem aumento de custos. Essas enzimas são utilizadas após o corte da matéria-prima, para macerar a polpa até a liquefação parcial ou total da fruta, diminuindo o tempo de processamento e melhorando a extração dos componentes da fruta. Após a extração, pectinases são adicionadas para clarificação e diminuição de viscosidade para facilitar a filtração e concentração ${ }^{1}$.

Em sucos clarificados, como no de maçã, as pectinases são utilizadas na separação de partículas sedimentáveis, na filtração ou centrifugação. As vantagens do uso de pectinases em sucos incluem: utilização em diversos tipos de produtos, isto é, sucos clarificados, não clarificados, concentrados, polpas, purês etc.; redução do tempo total para extração do suco em relação aos processos clássicos, auxiliam na produção de sucos e concentrados estáveis com redução de resíduos da polpa; custos de produção reduzidos e possibilidade de processamento de diferentes frutas ${ }^{28}$.

Em sucos não clarificados, como o de laranja, é feita a desnaturação da pectina esterase com o aquecimento do suco, para prevenir a perda da turbidez desejada, ou congela-se o suco concentrado para manter a enzima em estado inativo ${ }^{28}$. O tratamento térmico brando pode resultar em produtos de alta qualidade, com melhor qualidade de aroma e maior conteúdo vitamínico ${ }^{17}$. Durante o processo de extração do suco, as enzimas podem ser adicionadas no final da extração da polpa lavada para diminuir a viscosidade ou após a extração final, para aumentar a liberação de açúcares e sólidos solúveis, melhorando o rendimento e diminuindo a viscosidade. O tratamento enzimático melhora a estabilidade da turvação, pois a degradação da pectina é limitada ${ }^{28}$.

\section{Recuperação de óleos essenciais}

Os óleos essenciais estão localizados especialmente nas células do albedo de frutas cítricas e contêm hidrocarbonetos (terpenos e sesquiterpenos), compostos oxigenados (aldeídos, ésteres, álcoois, cetonas e fenóis) e resíduos não voláteis (ceras, flavonóides e ácidos graxos $)^{28}$. Após a extração do suco, as partículas de albedo e a emulsão óleo-água são separadas. Esta emulsão é passada em um ciclone e, a seguir, centrifugada para produzir uma emulsão rica em óleo, que é concentrada ${ }^{28}$. A aplicação de pectinases hidrolisa os complexos de pectina-proteína, liberando o óleo, aumentando o rendimento, diminuindo o tempo de processo e melhorando a qualidade do produto final ${ }^{5,28}$.

\section{Indústrias de vinhos}

Pectinases, em conjunto com $\beta$-glucanases e hemicelulases, têm sido utilizadas na produção de vinho. As vantagens do uso das três enzimas são: melhor maceração da casca e aumento da extração de pigmentos, facilita a clarificação e a filtração do mosto e aumenta a qualidade e a estabilidade do vinho ${ }^{1,41,42}$.

A adição de pectinases durante o esmagamento das uvas ou no mosto de vinho melhora a extração do suco, reduz o tempo de clarificação e aumenta o conteúdo de terpenos no vinho. Preparações comerciais de pectinases com alta atividade de pectina liase e baixa atividade de pectina metil esterase são preferidas por minimizarem a liberação de metanol dos ácidos poligalacturônicos metilados durante a produção de vinho ${ }^{1}$.

Enzimas pectinolíticas adicionadas durante a maceração das uvas para produção de vinho tinto resultam no melhoramento das características visuais (cor e turbidez), quando comparadas com vinhos não tratados, apresentando características cromáticas consideradas melhores que os vinhos controle .

\section{Extração de óleos vegetais}

Óleos de canola, coco, semente de girassol, palma e oliva são tradicionalmente produzidos por extração com solventes orgânicos, mais comumente o hexano. A degradação da parede celular por enzimas pectinolíticas permite seu uso para extração de óleo vegetal em processo aquoso, pela liquefação dos componentes estruturais das paredes celulares das sementes que contêm óleo ${ }^{28}$.

Preparações comerciais enzimáticas contendo pectinases, celulases e hemicelulases começaram a ser utilizadas para extração de óleo de oliva, sendo adicionadas durante a prensagem das azeitonas para melhorar o processo de extração ${ }^{1,28}$.

$\mathrm{O}$ uso de enzimas de maceração aumenta a quantidade de agentes anti-oxidantes e de vitamina E em óleo de oliva extravirgem, reduze a indução ao ranço, aumenta a extração, melhora o fracionamento na centrifugação e produz óleo com baixo teor de umidade ${ }^{1}$.

\section{Alimentos funcionais}

Pectina e polissacarídeos pécticos estão emergindo como ingredientes alimentares bioativos. Pectina de grapefruit, usado industrialmente como estabilizante e como suplemento de alimentos infantis, melhora a nutrição e o desenvolvimento físico infantil ${ }^{14}$. Esses oligogalacturonídeos e seus produtos de degradação por enzimas pectinolíticas são classificados como "probióticos", por serem não digeríveis, ou seja, não são hidrolisados na parte superior do trato gastrintestinal, e podem ser usados como promotores de saúde em nutrição humana e animal por estimularem seletivamente o crescimento e/ou a atividade de espécies de bactérias residentes no colo intestinal ${ }^{14}$.

\section{Melhoramento na extração de amido de mandioca}

Polpa de mandioca, o resíduo sólido produzido após a extração do amido, contém uma proporção significante de grânulos de amido (68\%, base seca) e de fibras (27\%, base seca). O alto conteúdo de fibras provavelmente diminui a extração do amido remanescente, mantendo os grânulos juntos e presos em uma rede fibrosa, que pode ser rompida por métodos enzimáticos, baseados na aplicação de uma mistura de pectinases e celulases que destroem a integridade estrutural da matriz responsável pelo aprisionamento dos grânulos, expondo e liberando o amido ${ }^{43}$. 


\section{Fermentação de café e chá}

Pectinases são importantes na fermentação de café e chá, pois aceleram o processo de fermentação $0^{28,44}$, melhorando a qualidade do produto final ${ }^{19}$.

Enzimas pécticas são adicionadas para remover a camada de mucilagem do grão, constituída de três quartos de substâncias pécticas. Celulases e hemicelulases, presentes em preparações comerciais, são aspergidas nos grãos, acelerando o processo de fermentação. Como o tratamento dos grãos de café em larga escala com enzimas comerciais é custoso e não econômico, são utilizadas enzimas pécticas microbianas obtidas da fermentação de resíduos da mucilagem ${ }^{5,28}$.

\section{Indústria têxtil}

Enzimas pectinolíticas podem ser usadas nas indústrias têxteis para degradar a camada de pectina que recobre as fibras de celulose, liberando-as para posterior processamento ${ }^{28,45,46}$, no tratamento do resíduo líquido e na degomagem das fibras naturais ${ }^{18}$.

Pectinases alcalinas são utilizadas para maceração das fibras vegetais, como linho, cânhamo e juta, na biopreparação de algodão e no polimento enzimático de tecidos mistos de juta e algodão ${ }^{19}$.

A degomagem de fibras de rami com pectina liase produz fibras com qualidade superior àquelas produzidas por complexos enzimáticos comerciais ou utilizando processo químico com soda alcalina, além de reduzir a poluição ambiental provocada pela liberação da soda cáustica ${ }^{28,46}$.

Em algodão cru, a remoção da pectina, cera e agentes de goma com a utilização de pectinases em conjunto com amilases, lipases e hemicelulases em condições adequadas, substitui o uso da soda cáustica e gera produtos de alta qualidade, para posterior tingimento e processo de tecelagem com menor consumo de energia ${ }^{47}$.

\section{Indústria de papel e celulose}

Durante a fabricação de papel, pectinases podem despolimerizar substâncias pécticas e, subseqüientemente, diminuir a demanda catiônica das soluções pécticas e do filtrado resultantes do branqueamento com peróxido ${ }^{5}$, solucionar problemas de retenção no branqueamento mecânico da celulose e no tratamento dos efluentes dos moinhos de papel $^{19}$.

\section{Ração animal}

Pectinases são utilizadas em conjunto com outras enzimas para reduzir a viscosidade da ração animal, a fim de aumentar a absorção e a liberação de nutrientes através da hidrólise das fibras não biodegradáveis e dos nutrientes bloqueados pelas fibras ${ }^{5}$.

\section{CONSIDERAÇÕES FINAIS E PERSPECTIVAS}

Muitos estudos têm sido realizados para isolamento, seleção, produção, caracterização e aplicações de enzimas pectinolíticas não somente em processamento de alimentos, mas também para outras aplicações industriais.

A elucidação de pectinases através de técnicas de alta resolução, como cristalografia e ressonância nuclear magnética, está sendo realizada, permitindo o entendimento de mecanismos regulatórios de secreção destas enzimas molecularmente e da sua ação catalítica nas substâncias pécticas.

O melhoramento da produção de pectinases pode ser obtido por técnicas moleculares, como DNA recombinante ou mutação randômica, e os genes podem ser facilmente introduzidos em mi- crorganismos selecionados, que utilizam esse novo material genético através de uma expressão direta. Leveduras normalmente não produzem ou não secretam pectina metil esterase, entretanto, suas pectinases podem ser usadas na clarificação de sucos e vinhos, indicando que genes codificadores de pectinases têm sido clonados com sucesso e introduzidos em cepas de Saccharomyces cerevisiae codificadores de enzimas biologicamente ativas ${ }^{17}$.

A importância biotecnológica de microrganismos e de suas enzimas promove um grande interesse em direção ao entendimento da regulação e da expressão gênica de enzimas extracelulares. $\mathrm{O}$ número de seqüenciamentos genéticos tem aumentado rapidamente, disponibilizando informações para genômica comparativa, elucidação de rotas regulatórias e para estudos quantitativos de polissacarídeos vegetais e seus derivados.

\section{AGRADECIMENTOS}

À Fundação de Amparo à Pesquisa do Estado de São Paulo, FAPESP, pela bolsa de mestrado concedida.

\section{REFERÊNCIAS}

1. Bhat, M. K.; Biotechnol. Adv. 2000, 18, 355.

2. Kashyap, D. R.; Chandra, S.; Kaul, A.; Tewari, R.; World J. Microbiol. Biotechnol. 2000, 16, 277.

3. Gummadi, S. N.; Panda, T.; Process Biochem. 2003, 38, 987.

4. Sakai, T.; Sakamoto, T.; Hallaert, J.; Vandamme, E.; Adv. Appl. Microbiol. 1993, 39, 213.

5. Jayani, R. S.; Saxena, S.; Gupta, R.; Process Biochem., no prelo.

6. Alkorta, I.; Garbisu, C.; Llama, M. J.; Serra, J. L.; Process Biochem. 1998, $33,21$.

7. Almeida, C.; Brányik, T.; Moradas-Ferreira, P.; Teixeira, J.; Process Biochem. 2005, 40, 1937.

8. Limberg, G.; Körner, R.; Buchholt, H. C.; Christensen, T. M. I. E.; Roepstorff, P.; Mikkelsen, J. D.; Carbohydr. Res. 2000, 327, 293.

9. Vilariño, C.; Del Giorgio, J. F.; Hours, R. A.; Cascone, O.; Lebensm.-Wiss. u. Technol. 1993, 26, 107.

10. Whitaker, J. R.; Principles of Enzimology for the Food Sciences, $2^{\text {nd }}$ ed., Marcel Dekker, Inc.: New York, 1994, p. 425 - 436.

11. Maiorano, A. E.; Tese de Doutorado, Universidade de São Paulo, Brasil, 1990.

12. da Silva, E. G.; Borges, M. F.; Medina, C.; Piccoli, R. H.; Schwan, R. F.; FEMS Yeast Res. 2005, 5, 859 .

13. Fernández-González, M.; Úbeda, J. F.; Vasudevan, T. G.; Otero, R. R. C.; Biones, A. I.; FEMS Microbiol. Lett. 2004, 237, 261.

14. Lang, C.; Dörnenburg, H.; Appl. Microbiol. Biotechnol. 2000, 53, 366.

15. Gainvors, A.; Frézier, V.; Lemaresquier, H.; Lequart, C.; Aigle, M.; Belarbi, A.; Yeast 1994, 10, 1311.

16. Tsuyumu, S.; Ishii, S.; Nakamura, M.; Agricultural and Biological Chemistry 1989, 53, 2509.

17. Sorensen, J. F.; Krag, K. M.; Sibbesen, O.; Delcur, J.; Goesaert, H.; Svensson, B.; Tahir, T. A.; Brufau, J.; Perez-Vendrell, A. M.; Bellincamp, D.; D’Ovidio, R.; Camardella, L.; Giovane, A.; Bonnin, E.; Juge, N.; Biochim. Biophys. Acta 2004, 1696, 275

18. Kaur, G.; Kumar, S.; Satyanarayama, T.; Bioresour. Technol. 2004, 94, 239.

19. Sharma, D. C.; Satyanarayama, T.; Bioresour. Technol., no prelo.

20. Souza, J. V. B.; Silva, E. S.; Maia, M. L. S.; Teixeira, M. F. S.; Process Biochem. 2003, 39, 455.

21. Taragano, V. M.; Pilosof, A. M. R.; Enzyme Microb. Technol. 1999, 25, 411.

22. Zheng, Z.; Shetty, K.; Process Biochem. 2000, 35, 825.

23. Blandino, A.; Dravillas, K.; Cantero, D.; Pandiella, S. S.; Webb, C.; Process Biochem. 2001, 37, 497

24. Lima, A. S.; Alegre, R. M.; Meirelles, A. J. A.; Carbohydr. Polym. 2000, 50, 63

25. de Gregorio, A.; Mandalani, G.; Arena, N.; Nucita, F.; Tripodo, M. M.; lo Curto, R. B.; Bioresour. Technol. 2002, 83, 89

26. Silva, D.; Tokuioshi, K.; Martins, E. S.; da Silva, R.; Gomes, E.; Process Biochem. 2005, 40, 2885.

27. Uenojo, M.; Dissertação de Mestrado, Universidade Estadual de Campinas, Brasil, 2003.

28. Kayshap, D. R.; Vohra, P. K.; Chopra, S.; Tewari, R.; Bioresour. Technol. 2001, $77,215$.

29. Shen, Z.; Manning, G.; Reese, J. C.; Reeck, G. R.; Insect Biochem. Mol. Biol. 1999, 29, 209. 
30. Rizzatto, M. L.; Dissertação de Mestrado, Universidade Estadual de Campinas, Brasil, 1999.

31. Mutlu, M.; Sarioglu, K.; Demir, N.; Ercan, M. T.; Acar, J.; J. Food Eng. 1999, $41,147$.

32. Karam, N. E.; Belarbi, A.; World J. Microbiol. Biotechnol. 1995, 11, 559.

33. Mayans, O.; Scott, M.; Connerton, I.; Gravesen, T.; Benen, J.; Visser, J.; Pickersgill, R.; Jenkins, J.; Structure 1997, 5, 677.

34. Soccol, C. R.; Vandenberghe, L. P. S.; Biochem. Eng. J. 2003, 13, 205.

35. Brand, D.; Pandey, A.; Roussos, S.; Soccol, C. R.; Enzyme Microb. Technol. 2000, 27, 127.

36. Medeiros, A. B. P.; Pandey, A.; Freitas, R. J. S.; Christen, P.; Soccol, C. R.; Biochem. Eng. J. 2000, 6, 33.

37. Sarioglu, K.; Demir, N.; Acar, J.; Mutlu, M.; J. Food Eng. 2001, 47, 271

38. Tajchakavit, S.; Boye, J. I.; Couture, R.; Food Res. Int. 2001, 34, 415.

39. Vaillant, F.; Millan, A.; Millan, P.; Dornier, M.; Decloux, M.; Reynes, M.; Process Biochem. 2000, 35, 989.
40. Demir, N.; Acar, J.; Sarioglu, K.; Mutlu, M.; J. Food Eng. 2001, 47, 275

41. Férnandez, M.; Úbeda, J. F.; Briones, A. I.; Int. J. Food Microbiol. 2000, 59, 29.

42. Takayanagi, T.; Uchibori, T.; Yokutsuka, K.; American Journal of Enology \& Viticulture 2001, 52, 41.

43. Sriroth, K.; Chollakup, R.; Chotineeranat, S.; Piyachomkwan, K.; Oates, C. G.; Bioresour. Technol. 2000, 71, 63.

44. Silva, C. F.; Schwan, R. F.; Dias, E. S.; Wheals, A. E.; Int. J. Food Microbiol. 2000, 60, 251.

45. Minussi, R. C.; Bacarat-Pereira, M. C.; Coelho, J. L. C.; Silva, D. O.; Lett Appl. Microbiol. 1997, 24, 369.

46. Piccoli-Valle, R. H.; Passos, F. M. L.; Passos, F. J. V.; Silva, D. O.; Brazilian J. Microbiol. 2001, 32, 135 .

47. Sawada, K.; Ueda, M.; J. Biotechnol. 2001, 89, 263. 